\title{
Antioxidant enzymes as biochemical markers for sharka resistance in apricot
}

\author{
J.A. HERNÁNDEZ ${ }^{1}$, J. CANO, B. PORTILLO, M. RUBIO and P. MARTÍNEZ-GÓMEZ
}

Departamento de Mejora y Fisiología Vegetal, CEBAS-CSIC, PO Box 164, E-30100 Espinardo, Murcia, Spain.

\begin{abstract}
The activity of antioxidant enzymes in different apricot cultivars, resistant or susceptible to PPV, was analyzed during the years 2002 and 2003. Resistant cultivars showed higher activities of antioxidant enzymes such as catalase (CAT), ascorbate peroxidase (APX) and dehydroascorbate reductase (DHAR) than susceptible cultivars. Five superoxide dismutase (SOD) isozymes (CuZn-SODs) were detected in the apricot cultivars. However, no correlation was observed between this isozyme pattern and the resistance to PPV. On the other hand, PPV-resistant apricot cultivars showed a greater capability for elimination of $\mathrm{H}_{2} \mathrm{O}_{2}$ and recycling of ascorbate-glutathione cycle (ASC), and they have at least two of these enzymatic activities (CAT, APX and DHAR) over the average. This fact could contribute, among other factors, to their resistance to PPV. In contrast, this response was not observed in the susceptible cultivars. All these data suggest that the activity level of antioxidant enzymes CAT, APX and DHAR could be used as biochemical markers of PPV resistance in apricot and open a way for the further studies necessary for a better understanding of the role of antioxidant enzymes in the PPV resistance in Prunus.
\end{abstract}

Additional key words: Prunus armeniaca, Plum pox virus, susceptibility

Abbreviations: AOS - activated oxygen species; APX - ascorbate peroxidase; ASC-GSH cycle - ascorbate-glutathione cycle; CAT - catalase; CuZn-SOD - copper,zinc-containing superoxide dismutase; DHAR - dehydroascorbate reductase; Fe-SOD - iron-containing superoxide dismutase; GR - glutathione reductase; GPX - glutathione peroxidase; $\mathrm{H}_{2} \mathrm{O}_{2}$ hydrogen peroxide; MDHAR - monodehydroascorbate reductase; Mn-SOD - manganesecontaining superoxide dismutase; $\mathrm{O}_{2}{ }^{-}$- superoxide radicals; $\mathrm{OH}$ - hydroxyl radicals; POX peroxidase; PPV - Plum pox virus; SEO - Stark Early Orange; SOD -superoxide dismutase; WCIMV - White clover mosaic potexvirus.

Acknowledgements: The authors thank Dr. Federido Dicenta for technical assistance in the statistical analysis. This research has been supported by grants AGL 2002-02115 from the CICYT (Spanish Ministry of Science and Technology) and PB/47/FS/02 from the Region of Murcia.

${ }^{1}$ Author for correspondence; fax: (+34) 9683962 13, e-mail: jahernan@cebas.csic.es 


\section{Introduction}

Sharka, a disease caused by Plum pox virus (PPV), is a serious limiting factor for temperate fruit production in affected areas. PPV affects most Prunus species, resulting in severe economic losses in apricot, plum, prune and peach (Németh 1994). Described for the first time in Bulgaria in 1917, sharka has spread throughout Europe, North Africa, India and Chile, and, more recently, to North America (Kölber 2001).

This viral disease is characterized by its difficult control, due to its easy transmission by aphids. Short-term control methods in the field include removal of diseased plants and planting of certified material. However, the release and cultivation of new resistant cultivars seems to be the definitive solution. The development of new resistant apricot genotypes and the search for new sources of resistance to sharka are two of the most important objectives in apricot breeding programmes (Audergon et al. 1994, Martínez-Gómez and Dicenta 2000). Evaluation of PPV resistance in controlled conditions is a time-consuming and expensive process (Martínez-Gómez and Dicenta 1999). Therefore, the search for biochemical and molecular markers associated with resistance would be of a great interest.

Plants possess several mechanisms that detoxify superoxide radicals $\left(\mathrm{O}_{2}{ }^{-}\right)$and hydrogen peroxide $\left(\mathrm{H}_{2} \mathrm{O}_{2}\right)$, called antioxidant systems. The primary components of these antioxidant systems include non-enzymatic antioxidants (carotenoids, ascorbate, glutathione and tocopherols) and enzymes such as superoxide dismutase (SOD, EC 1.15.1.1), catalase (CAT, EC 1.11.1.6), glutathione peroxidase (GPX, EC 1.11.1.9), peroxidases (POX, EC 1.11.1.7), and the enzymes involved in the ascorbate-glutathione cycle (ASC-GSH cycle), ascorbate peroxidase (APX, EC 1.11.1.1), dehydroascorbate reductase (DHAR, EC 1.8.5.1), monodehydroascorbate reductase (MDHAR, EC 1.6.5.4) and glutathione reductase (GR, EC 1.6.4.2) (Hernández et al. 2000, Jiménez et al. 1997). 
Activated oxygen species (AOS), including $\mathrm{H}_{2} \mathrm{O}_{2}, \mathrm{O}_{2}{ }^{-{ }^{-}}$and hydroxyl radicals ( $\mathrm{OH}$ ), are involved in plant responses to pathogen infections (Baker and Orlandi 1995). Hydrogen peroxide has been implicated in direct killing of pathogens and host cells. In addition, AOS may function as part of a signal transduction pathway leading to the induction of PR protein synthesis and systemic resistance in infected and non-infected parts of plants (Mehdy et al. 1996). Hernández et al. (2001a) suggested an important role for $\mathrm{H}_{2} \mathrm{O}_{2}$ in the response of apricot cultivars to PPV.

It has been proposed that a decline in AOS-scavenging capacity may be required before a rapid increase in virus replication can take place. In Phaseolus vulgaris L. plants treated with the cytokinin dihydrozeatin, salicylic acid or jasmonic acid showed elevated CAT, GR and peroxidase activities. These treatments, when applied before inoculation with WCIMV (White clover mosaic potexvirus), inhibited virus replication and symptom development (Clarke et al. 2002). It is possible that, in some plant-virus interactions, the maintenance of enzymes involved in antioxidant metabolism prevents the establishment of the virus and the progression of the disease (Clarke et al. 2002, Deak et al. 1999). It is also possible that a decline in antioxidant enzymes and an increase in AOS could be necessary for the establishment of infection and the replication and spread of some plant viruses. All these data suggest that an enhanced capability for elimination of AOS could play a role in avoiding or hindering the replication of plant virus. Recently, it has been suggested the involvement of the glucose-6-phosphate dehydrogenase, the key enzyme of the oxidative pentose phosphate pathway, not only in the biosynthesis of nucleotide precursors but also in others processes, possibly connected with defense mechanisms of plant host against virus infection (Sindelárova and Sindelar 2003/4).

In this work, we examined antioxidant enzyme activity in different PPV-resistant and PPV-susceptible non-infected apricot cultivars, to evaluate if any differences exist in 
the constitutive levels of these antioxidant enzymes, and to correlate enzymatic levels with the PPV-susceptibility/resistance character in apricot.

Material and Methods

\section{Plant material}

Plant material assayed included three traditional Spanish cultivars (Canino, Currot, and Real Fino) and a new selection from the CEBAS-CSIC (Z50308), all these cultivars described as susceptible to PPV. On the other hand, four representative North American apricot cultivars [Goldrich, Orange Red, Stark Early Orange (SEO), and Stella] described as PPV-resistant were also included in the study (Martínez-Gómez and Dicenta 2000) (Table 1). Apricot trees were grown in an experimental orchard in Cieza (South-East Spain). Fully expanded green young leaves were randomly sampled in the sun-faced parts of the trees and they were taken at the same level. Activities of antioxidant enzymes were evaluated during years 2002 and 2003. Five samples from each apricot cultivar were analyzed during the two year of the study.

\section{Leaf enzyme extraction}

All operations were performed at $0-4{ }^{\circ} \mathrm{C}$. Leaf material (2g fresh mass), from the different apricot cultivars, was homogenized with $4 \mathrm{~cm}^{3}$ of an ice-cold medium containing 50 mM K-phosphate (pH 7), 0.1 mM EDTA, 5 mM cysteine, $10 \%$ (m/v) insoluble PVPP (polyvynylpolypyrrolidone), $0.1 \mathrm{mM}$ PMSF (phenylmethanesylfonyl fluoride) and $0.2 \%$ (v/v) Triton X-100. For the APX activity assay, $20 \mathrm{mM}$ Na-ascorbate was added to the extraction medium. The extracts were filtered through two layers of nylon cloth and 
centrifuged at $8000 \mathrm{~g}$ for $20 \mathrm{~min}$, at $4{ }^{\circ} \mathrm{C}$. The supernatant fractions were then filtered on Sephadex G-50 M PD10 columns (Amersham Pharmacia Biotech. Wien, Austria) equilibrated with the extraction medium.

\section{Enzymatic determinations and assays}

APX, DHAR, MDHAR and GR activities were assayed as described in Hernández et al. (2000). Enzyme activities were corrected for non-enzymatic rates and for interfering oxidation. For APX, the oxidation rate of ascorbate was estimated between 1.0 and $60 \mathrm{~s}$ after starting the reaction with the addition of $\mathrm{H}_{2} \mathrm{O}_{2}$. Correction was made for the low nonenzymatic oxidation of ascorbate by $\mathrm{H}_{2} \mathrm{O}_{2}$. To determine MDHAR activity, the monodehydroascorbate was generated by the ascorbate/ascorbate oxidase system. The rate of monodehydroascorbate-independent NADH oxidation (without ascorbate and ascorbate oxidase) was subtracted from the initial monodehydroascorbate-dependent NADH oxidation rate (with ascorbate and ascorbate oxidase). For DHAR activity, the reaction rate was corrected for the non-enzymatic reduction of DHA by GSH. A 2\% contribution to the absorbance by GSSG was also taken into account. Values of GR activity were corrected for the small, non-enzymatic oxidation of NADPH by GSSG (Jiménez et al., 1997). Total SOD activity was determined according to McCord and Fridovich (1969). Proteins were estimated according to Bradford (1976). SOD isozymes were separated by PAGE on 10\% gels using a Bio Rad Mini Protean II dual slab cell, and they were localised by the photochemical method (Weissiger and Fridovich 1973). Assignment of the different SOD isoforms (CuZn-SOD, Mn-SOD and Fe-SOD) was performed by selective inhibition with $\mathrm{KCN}$ or $\mathrm{H}_{2} \mathrm{O}_{2}$ (Hernández et al. 2001b). Cu,Zn-SODs are inhibited by $\mathrm{CN}^{-}$ and $\mathrm{H}_{2} \mathrm{O}_{2}$, Fe-SODs are resistant to $\mathrm{CN}^{-}$but inactivated by $\mathrm{H}_{2} \mathrm{O}_{2}$, and Mn-SODs are resistant to both inhibitors (Bridges and Salin 1981). 


\section{Data analysis}

An analysis of variance (ANOVA) of the antioxidant enzyme activities was performed using Duncan's multiple range test, to identify significant differences among means. Band scoring and separation of the activities of SOD isozymes were performed using GeneTools gene analysis software (SYNGENE, Beacon House, Cambridge, UK).

\section{Results}

CAT, POX, MDHAR and DHAR activities differed from year to year (Table 2). However, only CAT, MDHAR and DHAR activities were significantly higher in the year 2002 than in 2003, whereas POX activity did not show significant change (Table 3). Antioxidant enzyme activities showed differences when the ANOVA was applied to cultivars, except for SOD activity. However, there was no significant Year * Variety interaction (Table 2).

No clear correlation could be observed in the POX, MDHAR, DHAR, GR and SOD activities when the different apricot cultivars were analyzed regarding their level of susceptibility/resistance. However, and with a few exceptions, a clear tendency can be observed in the CAT, APX and DHAR activities. In this case, it seems that resistant apricot cultivars showed higher constitutive activity for these antioxidant enzymes than the susceptible cultivars (Table 3).

According to the Duncan's test, resistant cultivars showed higher activities for CAT, APX and DHAR than the susceptible cultivars (Table 3). However, it is important to note that, in the case of CAT, the higher activities corresponded to the susceptible cultivar Real Fino and all the resistant cultivars (Table 2). For APX, with the exception of the cultivar Currot, the higher activities corresponded to the resistant cultivars. Finally, for DHAR, the resistant cultivars Stella, Goldrich and SEO showed the highest activity values. However, only the resistant apricot cultivars have at least two of these enzymatic 
activities over the total average showed in Table 3, and Stella has the three antioxidant enzymes over this total average.

Only CuZn-SODs isozymes were detected after 10\% PAGE, according to their sensitivity to $\mathrm{H}_{2} \mathrm{O}_{2}$ and $\mathrm{KCN}$. The apricot cultivars analyzed can be placed in three groups according to the number of their SOD isozyme: Group 1) Stella, Orange Red and Real Fino; Group 2) Goldrich, SEO, and Canino; and Group 3) Currot and Z50308. The first group seems to have three CuZn-SODs, named 1, 2 and 3, respectively, in order of increasing mobility, and with Rf values of $0.400,0.466$ and 0.533 , respectively. In contrast, group 2 seems to have five CuZn-SODs, named 1 to 5 in order of increasing electrophoretic mobility. CuZnSODs 1, 2 and 3 had similar Rf values to cultivars from group 1, and CuZn-SODs 4 and 5 had Rf values of 0.560 and 0.600 , respectively. However, group 3 also has three CuZn-SOD isoforms, named CuZn-SOD 1, 2' and 5. Whereas CuZnSODs 1 and 5 had Rf values similar to those of groups 1 and 2, CuZn-SOD 2' had a higher electrophoretic mobility (0.493) than CuZn-SOD 2 from the other groups, and, accordingly, we named it CuZn-SOD 2' (Table 4, Fig. 1).

No correlations can be observed between isozyme pattern and resistance or susceptibility to PPV. Similarly, the analysis of the different CuZn-SODs isozymes did not reveal any important differences in behavior between resistant and susceptible cultivars. The susceptible cultivar Z50308 had the highest values for CuZn-SODs 1 and 2', whereas the resistant Orange Red and the susceptible Real Fino and Canino exhibited the highest values for CuZn-SOD 2. The susceptible cultivar Canino also showed the highest activity for CuZn-SOD 4, whereas the resistant Stella and Orange Red cultivars and the susceptible Z50308 showed the higher values for CuZn-SOD 3. Finally, no significant differences were observed in CuZn-SOD 5 (Table 4). 


\section{Discussion}

The PPV-resistant apricot cultivars analyzed had a higher capability for elimination of $\mathrm{H}_{2} \mathrm{O}_{2}$ and recycling of ASC, and they have at least two of these enzymatic activities (CAT, APX and DHAR) over the total average. These facts could contribute to their resistance. However, this response was not showed by the susceptible cultivars.

In previous work carried out with two apricot cultivars, grown in controlled conditions in an insect-proof greenhouse and inoculated by chip grafting, we showed different behavior of SODs $\left(\mathrm{H}_{2} \mathrm{O}_{2}\right.$-generating enzymes) and APX (an $\mathrm{H}_{2} \mathrm{O}_{2}$-removing enzyme) in both cultivars. In the resistant cultivar studied (Goldrich), PPV infection produced an induction of SOD activity, whereas no change in APX was observed. However, in the susceptible cultivar (Real Fino), inoculation with PPV brought about a decrease in SOD and a rise in APX activity. These results suggested an important role for $\mathrm{H}_{2} \mathrm{O}_{2}$ in the response to PPV in the resistant cultivar (Hernández et al. 2001a). Under control conditions, the susceptible cultivar had higher SOD, APX and DHAR activities than the resistant cultivar, which had higher MDHAR activity values (Hernández et al. 2001a). However, under non-inoculated field conditions, our present results showed that resistant cultivars had higher APX, CAT and DHAR values than susceptible cultivars.

After 10\% PAGE of crude leaf extracts from the different apricot cultivars, only CuZn-SOD isozymes were detected. In contrast, in other woody plants, such as poplar and lemon trees, the presence of Mn-SOD, CuZn-SOD, and Fe-SOD was described (Almansa et al. 2002, Bernardi et al. 2004). The presence of only CuZn-SOD isozymes was observed previously in greenhouse-grown apricot plants (Hernández et al. 2001a). The presence of only CuZn-SOD isozymes is surprising, because these isozymes are inhibited by $\mathrm{H}_{2} \mathrm{O}_{2}$, which is produced in different cell compartments (Halliwell and Gutteridge 1989), such as mitochondria and peroxisomes, where the presence of the $\mathrm{H}_{2} \mathrm{O}_{2}$-resistant Mn-SOD has been described (Del Rio et al. 1985, Sandalio and Del Rio 1987). In 
glyoxisomes of watermelon, as well as in wheat germ and pea leaves, a partly $\mathrm{H}_{2} \mathrm{O}_{2}$ sensitive CuZn-SOD isozyme has been described (Del Rio et al. 1985, Sandalio and Del Rio 1987, Beauchamp and Fridovich 1973). However, no correlation was observed between SOD isozyme pattern and the resistance and/or susceptibility to PPV. The fact that Currot and Z50308 had the same SOD isozyme pattern is not surprising, because the hybrid Z50308 proceeds from the cross Currot $x$ SEO, from the apricot breeding programme of CEBAS-CSIC.

In conclusion, all these data suggest that activity level of some antioxidant enzymes as CAT, APX and DHAR could be used as biochemical markers of PPV resistance in apricots. We propose that if an apricot cultivar has at least two of these enzymatic activities over the total average, it could be considered as a putative PPVresistant. However, some exceptions were found in these results, and these data must be confirmed by the analysis of more resistant and susceptible apricot cultivars. These results open a new way for the further studies necessary for a better understanding of the possible use of antioxidant enzyme activities as biochemical markers for PPV resistance. 


\section{References}

Almansa, M.S., Hernández, J.A., Jiménez, A., Botella, M.A. Sevilla, F.: Influences of rootstock-scion combinations in the superoxide dismutase response to salt in Citrus trees. - Biol. Plant. 45: 545-549, 2002.

Audergon, J.M., Dosba, F., Karayiannis, I., Dicenta, F.: Amélioration de l’abricotier pour la résistance à la sharka. - EPPO Bull. 24: 741-748, 1994.

Baker, C.J., Orlandi, E.W.: Active oxygen in plant pathogenesis. - Annu. Rev. Phytopath. 33: 299-321, 1995.

Beauchamp, C.O., Fridovich, I.: Isozymes of superoxide dismutase from wheat germ. Biochim. biophys. Acta 317: 50-64, 1973.

Bernardi, R., Nali, C., Ginestri, P., Pugliesi, C., Lorenzini, G., Durante, M.: Antioxidant enzyme isoforms on gels in two polar clones differing in sensitivity after exposure to ozone. - Biol. Plant. 48: 41-48, 2004.

Bradford, M.M.: A rapid and sensitive method for the quantitation of microgram quantities of protein utilizing the principle of protein-dye binding. - Anal Biochem. 72: 248-254, 1976.

Bridges, S.M., Salin, M.: Distribution of ironcontaining superoxide dismutase in vascular plants. Plant Physiol. 68: 275-336, 1981.

Clarke, S.F., Guy, P.L., Burritt, D.J., Jameson, P.E.: Changes in the activities of antioxidant enzymes in response to virus infection and hormone treatment. Physiol. Plant. 114: 157-164, 2002.

Deak, M., Horvath, G.V., Davletova, S., Torok, K., Sass, L., Vass, I., Barna, B., Kiraly, Z., Dudits, D.: Plants ectopically expressing iron-binding protein, are tolerant to oxidative damage and pathogens. - Nature Biotechnol. 17: 192-196, 1999. 
Del Río, L.A., Sandalio, L.M., Yáñez, J., Gómez, M.: Induction of a manganesecontaining superoxide dismutase in leaves of Pisum sativum L. by high nutrient level of zinc and manganese. - J. inorg. Biochem. 24: 25-34, 1985.

Halliwell, B., Gutteridge, J.M.C.: Free Radicals in Biology and Medicine. Claredon Press, Oxford, England, 1989.

Hernández, J.A., Jiménez, A. , Mullineaux, P.M. , Sevilla, F.: Tolerance of pea (Pisum sativum L.) to long-term salt stress is associated with induction of antioxidant defences. - Plant Cell Environ. 23: 853-862, 2000.

Hernández, J.A., Talavera, J.M., Martínez-Gómez, P., Dicenta, F., Sevilla, F.: Response of antioxidative enzymes to plum pox virus in two apricot cultivars. - Physiol. Plant. 111: 313-321, 2001a.

Hernández, J.A., Ferrer, M.A., Jiménez, A. , Ros-Barceló, A., Sevilla, F.: Antioxidant systems and $\mathrm{O}_{2}{ }^{-} / \mathrm{H}_{2} \mathrm{O}_{2}$ production in the apoplast of Pisum sativum L. leaves, its relation with $\mathrm{NaCl}$-induced necrotic lesions in minor veins. - Plant Physiol. 127: 817-831, 2001b.

Jiménez, A., Hernández, J.A., del Río, L.A., Sevilla, F.: Evidence for the presence of the ascorbate-glutathione cycle in mitochondria and peroxisomes of pea leaves. - Plant Physiol. 114: 275-284, 1997.

Kölber, M.: Workshop on Plum pox. - Acta Hort. 550: 249-255, 2001.

Martínez-Gómez, P., Dicenta, F.: Evaluation of resistance to sharka in the breeding apricot program in CEBAS-CSIC in Murcia (Spain). - Acta Hort. 488: 731-736, 1999.

Martínez-Gómez, P., Dicenta, F.: Evaluation of resistance of apricot cultivars to a Spanish isolate of plum pox potyvirus (PPV). - Plant Breeding 119: 179-181, 2000. 
McCord, J.M., Fridovich, I.: Superoxide dismutase, an enzymic function for erythrocuprein. - J. Biol. Biochem. 244: 6049-6055, 1969.

Mehdy, M.C., Sharma, Y.K., Sathasivan, K., Bays, N.W.: The role of activated oxygen species in plant disease resistance. - Physiol. Plant. 98: 365-374, 1996.

Németh, M.: History and importance of plum pox in stone-fruit production. - EPPO Bull. 24: 525-537, 1994.

Sandalio, L.M., del Río, L.A.: Localization of superoxide dismutase in glyoxisomes from Citrullus vulgaris. Functional implication in cellular metabolism. - J.Plant Physiol. 127: 395-409, 1987.

Sindelárová, M., Sindelár, L.: Changes in glucose-6-phosphate dehydrogenase, ribonucleases, esterases and contents of viruses in potato virus $\mathrm{Y}$ infected tobacco superinfected with tobacco mosaic virus. - Biol. Plant. 47: 99-104, 2003/4.

Weissiger, R.A., Fridovich, I.: Superoxide dismutase, Organelle specificity. - J. biol. Chem. 248: 3582-3592, 1973. 
Table 1. Pedigree, origin and main agronomic characteristics (skin and flesh colors, and PPV resistance) of the apricot cultivars assayed.

\begin{tabular}{lccccc}
\hline Cultivar & Pedigree & Origin & Skin color & Flesh color $^{*}$ & PPV resistance $^{1}$ \\
\hline Goldrich & Sunglo x Perfection & USA & Orange & Orange & Resistant \\
Orange Red & Lasg. Mas x NAJ2 & USA & Red & Orange & Resistant \\
SEO & Unknown & USA & Yellow & Light Orange & Resistant \\
Stella & Unknown & USA & Dark Orange & Orange & Resistant \\
Canino & Unknown & Spain & Light Orange & Orange & Susceptible \\
Currot & Unknown & Spain & Cream & White-Orange & Susceptible \\
Real Fino & Unknown & Spain & Cream & White - Yellow & Susceptible \\
Z503/08 & Currot x SEO & Spain & Red-Orange & Light Orange & Susceptible \\
& & & & & \\
\hline
\end{tabular}

${ }^{1}$ PPV resistance level determined by Martínez-Gómez and Dicenta (2000). 
Table 2. ANOVA ( $P$ values $x$ 100) of the levels of antioxidant enzymes catalase (CAT), peroxidase (POX), ascorbate peroxidase (APX), monodehydroascorbate reductase (MDHAR), dehydroascorbate reductase (DHAR), glutathione reductase (GR) and superoxide dismutase (SOD), in different apricot cultivars, carried out during the years 2002-2003.

\begin{tabular}{lrrrrrrr}
\hline & CAT & POX & APX & MDHAR & DHAR & GR & SOD \\
\hline Year & 0.05 & 0.01 & 16.74 & 0.01 & 0.13 & 14.58 & 27.30 \\
Cultivar & 0.02 & 0.02 & 0.69 & 1.57 & 0.99 & 0.78 & 8.83 \\
Year * Cultivar & 6.6 & 34.45 & 65.45 & 16.54 & 53.05 & 21.4 & 56.59 \\
\hline
\end{tabular}


Table 3. Antioxidant enzyme activity variations with the year and the apricot cultivar. Catalase (CAT) and peroxidase (POX) are expresed as $\left[\mu \mathrm{mol} \mathrm{min}{ }^{-1}\right.$ (prot) $\mathrm{mg}^{-1}$ ], ascorbate peroxidase (APX), monodehydroascorbate reductase (MDHAR), dehydroascorbate reductase (DHAR) and glutathione reductase (GR) are expressed as [nmol min ${ }^{-1}$ (prot) mg${ }^{1}$ ], and superoxide dismutase (SOD) is expressed as [ $\mathrm{U} \mathrm{mg}^{-1}$ (prot)]. Different letters in the same column indicate significant differences according to Duncan's multiple range test ( $P$ $=0.05)$.

\begin{tabular}{lrrrrrrr}
\hline & CAT & POX & APX & MDHAR & DHAR & GR & SOD \\
\hline Year 2002 & $16.74 \mathrm{a}$ & $0.777 \mathrm{a}$ & $173.1 \mathrm{a}$ & $226.6 \mathrm{a}$ & $182.9 \mathrm{a}$ & $169.9 \mathrm{a}$ & $51.0 \mathrm{a}$ \\
Year 2003 & $7.76 \mathrm{~b}$ & $1.182 \mathrm{a}$ & $124.7 \mathrm{a}$ & $102.7 \mathrm{~b}$ & $102.7 \mathrm{~b}$ & $197.5 \mathrm{a}$ & $45.5 \mathrm{a}$ \\
& & & & & & & \\
Goldrich & $6.49 \mathrm{bc}$ & $0.84 \mathrm{~cd}$ & $177.3 \mathrm{~b}$ & $75.4 \mathrm{c}$ & $153.5 \mathrm{ab}$ & $218.2 \mathrm{abc}$ & $44.24 \mathrm{~b}$ \\
Orange Red & $14.67 \mathrm{ab}$ & $1.47 \mathrm{a}$ & $179.5 \mathrm{~b}$ & $116.3 \mathrm{bc}$ & $78.0 \mathrm{~b}$ & $165.8 \mathrm{bcd}$ & $51.30 \mathrm{ab}$ \\
SEO & $15.41 \mathrm{ab}$ & $1.12 \mathrm{bc}$ & $138.6 \mathrm{~b}$ & $158.0 \mathrm{ab}$ & $185.8 \mathrm{a}$ & $243.6 \mathrm{ab}$ & $39.82 \mathrm{~b}$ \\
Stella & $17.60 \mathrm{a}$ & $0.72 \mathrm{~d}$ & $343.1 \mathrm{a}$ & $156.4 \mathrm{ab}$ & $205.6 \mathrm{a}$ & $118.4 \mathrm{~d}$ & $37.39 \mathrm{~b}$ \\
Resistant cultivars & $13.71 \mathrm{a}$ & $1.04 \mathrm{a}$ & $209.6 \mathrm{a}$ & $128.3 \mathrm{a}$ & $158.2 \mathrm{a}$ & $186.7 \mathrm{a}$ & $43.20 \mathrm{a}$ \\
& & & & & & & \\
Canino & $4.31 \mathrm{c}$ & $0.93 \mathrm{~cd}$ & $91.3 \mathrm{~b}$ & $167.5 \mathrm{ab}$ & $142.7 \mathrm{ab}$ & $270.2 \mathrm{a}$ & $55.33 \mathrm{ab}$ \\
Currot & $7.83 \mathrm{bc}$ & $0.99 \mathrm{bcd}$ & $170.3 \mathrm{~b}$ & $164.1 \mathrm{ab}$ & $115.9 \mathrm{ab}$ & $187.8 \mathrm{bcd}$ & $39.14 \mathrm{~b}$ \\
Real Fino & $21.16 \mathrm{a}$ & $1.06 \mathrm{bc}$ & $107.5 \mathrm{~b}$ & $218.1 \mathrm{a}$ & $116.7 \mathrm{ab}$ & $146.2 \mathrm{~cd}$ & $43.61 \mathrm{~b}$ \\
Z50308 & $2.11 \mathrm{c}$ & $1.28 \mathrm{ab}$ & $89.2 \mathrm{~b}$ & $104.6 \mathrm{bc}$ & $55.2 \mathrm{~b}$ & $146.7 \mathrm{~cd}$ & $65.65 \mathrm{a}$ \\
Susceptible cultivars & $8.85 \mathrm{~b}$ & $1.06 \mathrm{a}$ & $112.7 \mathrm{~b}$ & $161.9 \mathrm{a}$ & $104.6 \mathrm{~b}$ & $187.7 \mathrm{a}$ & $50.94 \mathrm{a}$ \\
& & & & & & & \\
\hline
\end{tabular}


Table 4. Activities of superoxide dismutase (SOD) isozymes [ $\mathrm{U} \mathrm{mg}^{-1}$ (prot)] in leaves from healthy apricot cultivars resistant (Stella, Goldrich, Orange Red, SEO) and susceptible (Canino, Currot, Real Fino, Z50308) to PPV. Different letters in the same column indicate significant differences according to Duncan's multiple range test $(P=$ $0.05)$.

\begin{tabular}{lrrrrrr}
\hline & CuZn-SOD1 & CuZn-SOD2 & CuZn-SOD2 & CuZn-SOD3 & CuZn-SOD4 & CuZn-SOD5 \\
\hline Stella & $10.37 \pm 1.76 \mathrm{a}$ & $7.66 \pm 1.30 \mathrm{a}$ & No detected & $19.35 \pm 3.30 \mathrm{bc}$ & No detected & No detected \\
Goldrich & $11.57 \pm 2.10 \mathrm{a}$ & $8.76 \pm 1.50 \mathrm{a}$ & No detected & $8.14 \pm 1.46 \mathrm{a}$ & $6.52 \pm 1.17 \mathrm{a}$ & $9.24 \pm 1.60 \mathrm{a}$ \\
Orange Red & $23.22 \pm 2.78 \mathrm{~b}$ & $12.7 \pm 1.50 \mathrm{~b}$ & No detected & $15.39 \pm 2.02 \mathrm{~b}$ & No detected & No detected \\
SEO & $9.52 \pm 1.41 \mathrm{a}$ & $8.05 \pm 1.12 \mathrm{a}$ & No detected & $6.84 \pm 0.95 \mathrm{a}$ & $6.40 \pm 0.77 \mathrm{a}$ & $8.99 \pm 1.17^{\mathrm{a}}$ \\
& & & & & & \\
Canino & $13.72 \pm 2.06 \mathrm{a}$ & $11.25 \pm 1.68 \mathrm{~b}$ & No detected & $9.78 \pm 1.47^{\mathrm{a}}$ & $9.58 \pm 1.15 \mathrm{~b}$ & $10.98 \pm 1.65^{\mathrm{a}}$ \\
Currot & $14.01 \pm 2.66 \mathrm{a}$ & No detected & $9.83 \pm 1.47 \mathrm{a}$ & No detected & No detected & $15.25 \pm 2.75 \mathrm{a}$ \\
Real Fino & $11.93 \pm 2.98 \mathrm{a}$ & $11.63 \pm 2.33 \mathrm{~b}$ & No detected & $20.05 \pm 4.81 \mathrm{c}$ & No detected & No detected \\
Z50308 & $32.87 \pm 4.27 \mathrm{c}$ & No detected & $21.99 \pm 2.41 \mathrm{~b}$ & No detected & No detected & $10.79 \pm 1.4 \mathrm{a}$ \\
\hline
\end{tabular}


Fig. 1. Superoxide dismutase (SOD) isozyme patterns observed in leaves of different apricot cultivars. 1.- Stella, 2.- Orange Red, 3.- Real Fino, 4.- Goldrich, 5.- SEO, 6.Canino, 7.- Currot, 8.- Z50308. 


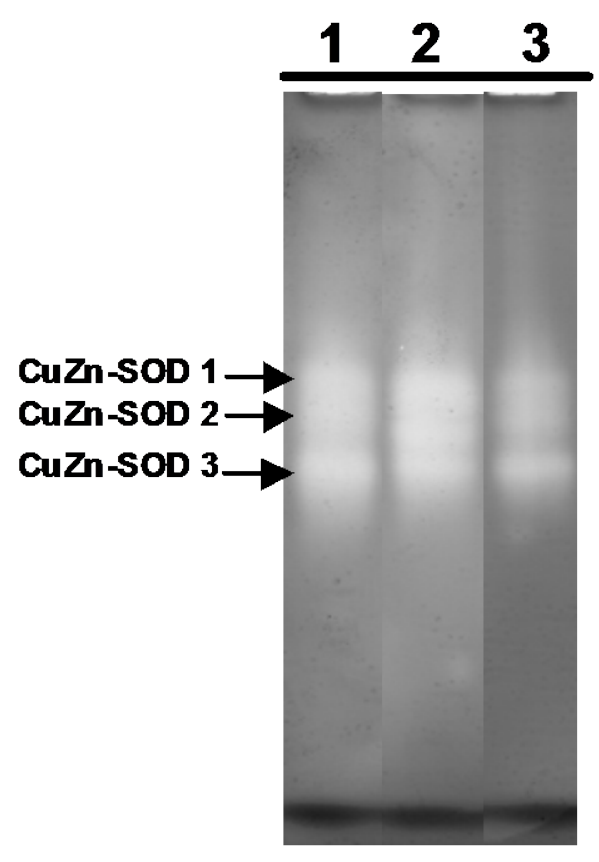

Group 1

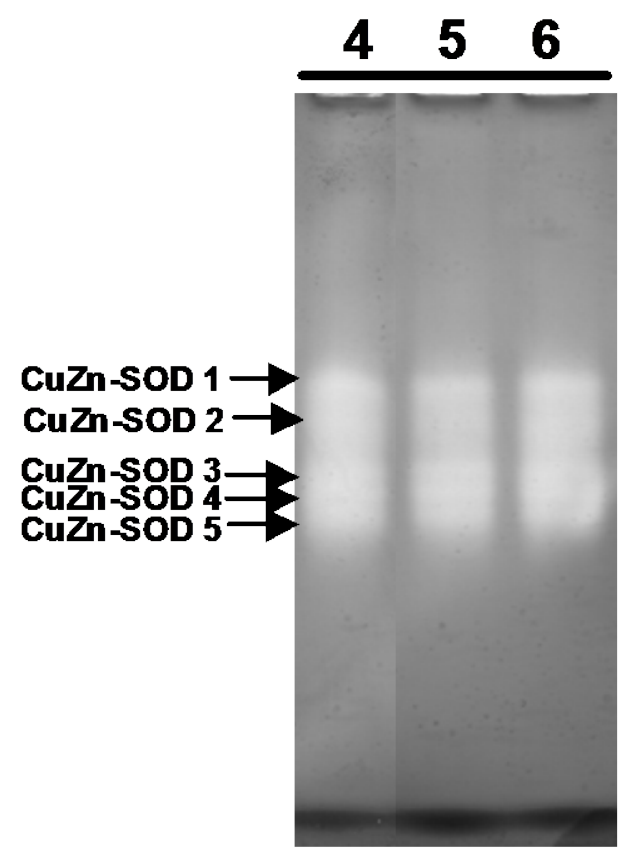

Group 2

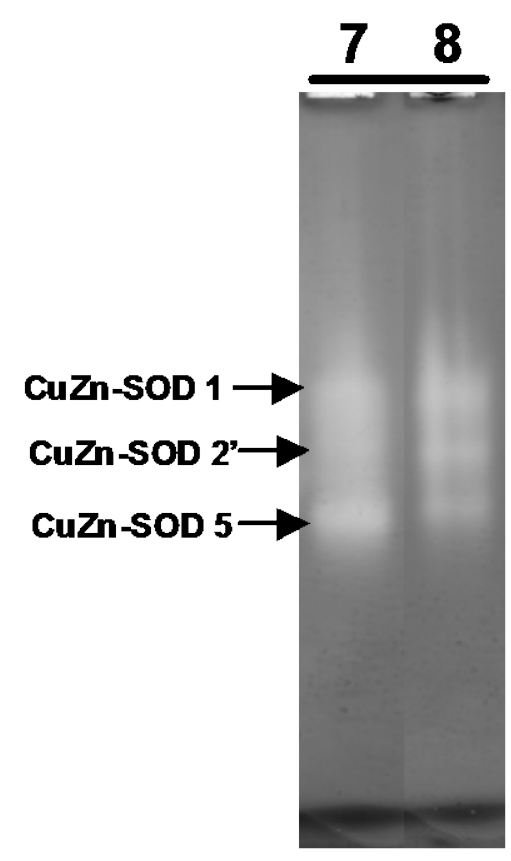

Group 3 